Moving in, out, through, and beyond the tensions between experience and social construction in somatic theory

By: Jill Green

Green, J. (2015). Moving in, out, and beyond the tensions between experience and social construction in somatic theory. Journal of Dance \& Somatic Practices, 7(1), 7-19.

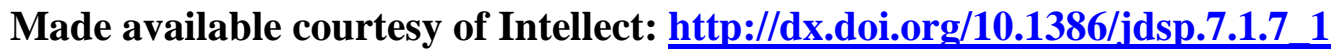

***;(C) Intellect. Reprinted with permission. No further reproduction is authorized without written permission from Intellect. This version of the document is not the version of record. Figures and/or pictures may be missing from this format of the document. ***

\begin{abstract}
:
This article is a reflexive analysis of the author's movement through the positions of different somatic theories. While some somatic theorists and practitioners focus on ideas of self and experiential knowledge, others are moving into a more postmodern realm by looking at bodies and somatic experience as social constructions. The author traces her movement through these theories and towards a non-binary postmodern view of somatics that does not dismiss the role of experience. Two narratives serve as a vehicle whereby the author wrestles with the issues.
\end{abstract}

Keywords: somatic theory | postpositivism| postmodernism | experiential knowledge | somatic epistemology | science

\title{
Article:
}

My whole professional life has been a struggle between an embrace of experiential knowledge and a realization of postmodern ideas related to sociocultural constructions of bodies. Pedagogically, I encourage my students to listen to their bodies. On the other hand, I discuss critical education theory, and how marginalized groups are often disenfranchised when addressing universalizing and essentialist ideas about bodies. My research agenda has included postpositivist methods and reflects postmodern ontologies and epistemologies. Yet, I use somatic sensitivity as a research tool and believe that it is helpful to find where one is bodily positioned before addressing how that position is influenced by social constructions of body, and somatics as a field of study.

Recently, I found myself in two professional predicaments, where I had to negotiate the binaries I had set for myself. I had to tread carefully because I did not want to simply romanticize the harmony between different philosophical arenas, without also being aware of the tensions between them. Yet, these situations put me in a position where I had to move through the binaries to come up with an inclusive framework that recognizes differences and the importance of a clear positionality, while transversing elements of diverse theoretical structures.

\section{The Tensions}


This article does not attempt to make an argument for the existence of binaries in experiential and postmodern world-views. Rather, it uses autonarrative as a way to negotiate the tensions in these perspectives that sometimes conflict and bump up against each other.

Narrative and autoethnography are key methodological tools in postpositivist research. Although I am not using this self-reflexive tool to study myself in the field, through this approach, I attempt to understand how my own narrative may explore questions about the social construction of knowledge. Thus, I am my own subject/participant in an investigation into the construction of beliefs about dance, somatics, and life. I use autonarrative as a methodological tool to explore diverse theoretical thought. In this sense the purpose is to triangulate theory, not only as a validity tool, but also as a way to negotiate meaning. Thus the intent of this article is to explore the differences in theories and challenge my own agendas. Reflexivity serves as a vehicle to see diverse theories and aspects, how they come together, and where they separate.

It is difficult to discuss categories and boundaries in postpositivist research because the boundaries can be blurry and theories juxtaposed to make new meanings. But categories and constructs may serve as a limited vehicle to look at differences.

When I speak about tensions, I am referring to places where world-views do not neatly fit together. For example, although I moved towards a post- modern sensibility and have questioned 'truths', I still find myself slipping into a strong experiential relationship with the world. I wrestled with the issues related to this mode of communicating with the world and the realization that my knowledge and experience are constructed and based on a sociocultural context. As postmodern theory questions relational aspects of research, universal assumptions, essentialist and foundational thinking, and even experience itself, I find a particular experiential connection to the world. Somatics has grounded me in this experiential aspect of being.

So my stories start with the assumption that there is a conflict between somatic practice and postmodern thought. While thinkers like Richard Shusterman (2008) strive to find connections between somatic theory and practice, and social and cultural aspects of the body, I believe that Shusterman, and many other somatic theorists, do not recognize the tensions between these modes of thought. As the first story develops, I do find that there is much crossover between somatic experiences and postmodern thought, but not in the ways that Shusterman and other somaticists claim.

My second narrative sets out to explain my ideas about social somatic theory and problematize the lack of emerging theory in the field of somatics that does not move beyond individual experience. I discuss the problems of including somatics under the umbrella of the 'dance sciences' - as is evident in many higher education programmes in dance in the United States - and my growing thought about the inappropriateness of using a scientific model for thinking about somatic practice. Science is based on different foundational views than somatics. While somatics recognizes firstperson views of the body, science tends to see the body as an objectified substance, studied from the outside. However again, I began to think more complexly when asked to participate in a quantitative and qualitative research programme begun in the sciences.

Thus, my intention is to look at the complexity of thought in these areas, while recognizing the differences. I problematize the binaries but also wish to account for the differences. 
Much of the first story includes a number of quotations because this situation arose when I was writing a particular chapter that propelled me to this way of thinking. I use this story as a methodological example to demonstrate how my research leads to theoretical considerations. However, I attempt to paraphrase as much as possible.

\section{From Humanism to Postmodernism ${ }^{1}$}

My first conundrum appeared when I was asked to write a chapter for a book about somatics and spirituality in dance. This task was challenging because while I had been immersed in postpositivist research and thinking for over 25 years, I struggled to reconcile my affinities for postmodernism and spirituality in dance. I published a number of articles and chapters about a postmodern and critical theory approach to somatics and dance (Green 1993, 1996a, 1996b, 1996c 1999, 2000, 2001a, 2001b, 2002-2003, 2004a, 2004b, 2007, 2008) while my scholarly interests shifted and changed. I moved to a more post- modern view, one that was reflected in my research methodology and belief that experience is socially, culturally and politically constructed.

My personal autobiographical narrative traces this theoretical transmigration and offers examples of my struggle to define spirituality, somatics and postmodernism. Throughout this narrative, I speak of spirituality as a connection to the world while somatics is a sensory experience. Although, somatics may be part of one's spirituality, spirituality is not necessarily part of somatics. The narrative begins when I was a little girl: As a child, I distinctly remember a number of times when I felt a deep connection to the world as I experienced a sense of heightened existence. Although I believe it was strange feeling this connection while so young, I continually sensed this feeling of attunement. When I started to dance, I was once again felt a strong state of connection. Dancing, for me, was always about a sense of engagement with something that seemed real and alive. While I was in my 20s I tried to search for my Jewish roots and attempted to find a synagogue that would meet my needs. When I was introduced to religion, however, I had an immediate resistance to the religious texts because, as I read them, they required that women give up their lives to their husbands and because they seemed to instill a sense of fear in God that did not make sense to me. I had a difficult time understanding the stories as 'real' and found myself disconnected from all organized religion. I saw religion as a patriarchal institution with the intent to keep its citizens in line and subservient to the particular religious system.

After an injury and while at New York University where I was doing my Masters degree, I began to find somatics when I studied with Elaine Summers in Kinetic Awareness®. Once again, I felt a deep sense of joy and connection doing the work. I entered the doctoral programme at Ohio State University with the intention to study somatics as a humanistic and self-affirming area of study. I felt that somatics could offer students a sense of wholeness and harmony, as I felt while working with dance and Kinetic Awareness ${ }^{\circledR}$.

However, I found my sense of the world shaken when I began to study with Patti Lather, a postmodern educational theorist, and find out about another world of thought, postmodernism. As with my earlier experience of organized religion, I began to think critically as I started to question what I knew and how I knew it. Postmodernism questions foundationalism, individualism, essence, 
experience, truth and even the idea of holism. It points to a plurality of truths and acknowledges difference and fragmentation. It investigates partial truths and reveals 'grand narratives' written by a dominant political authority.

So, I began to understand that my knowledge and experience are socially, culturally and politically constructed. I found that I valued a necessary change in thinking in such a multidimensional and growing diverse milieu. I came to believe that we cannot assume everyone experiences the world in the same way. In addition, I found postmodernism a creative venture - there was not always a black and white answer to the world, or to presenting or performing ideas. I was attuned to a world of complexity and juxtapositions of viewpoints and epistemologies.

When I was hired to teach in 'the Department of Dance at the University of North Carolina at Greensboro', I taught dance education and somatics. From the start of my career after my doctoral work, I used a postpositivist lens to see the world. Yet, while adhering to this approach, I found this sense of connection once again, when I found myself in North Carolina, remarried, and living on a fifteen-acre plot of land in the country. As a New York City native, I never quite experienced the trees, flora and fauna in such a connected and deeply felt way. I believed in a postmodern viewpoint but felt profoundly connected to the earth and life.

This postmodern turn left me in a difficult position. I was moved by postmodern thought and felt it was a way to celebrate difference and acknowledge those who may be disfranchised. Yet I did not want to give up on the idea of experience because it served me well in life and connected me to the world. It is the experiential and relational aspects of life that I did not seem willing to diminish. In addition, my work in somatics kept me grounded in this experiential aspect of being. I began to reframe somatics and see it through a postpositivist lens, cognizant of postmodern issues, yet open to experience (see Green 1993, 1996a, 1996b, 1996c, 1999, 2000, 2002-2003, 2004a, 2004b, 2007, 2008).

Within this world of conflicting positionalities, I asked, 'How could I negotiate the value of a somatic epistemology based in the world of experience and holism when I was recognizing the fragmentation of knowledge and the ways ideas of 'truth' bumped up against each other?' I began doing this by questioning assumptions that tend to guide the field of somatics, such as 'universal experience', 'holism' and the necessary goodness of somatic practice (Green in press).

So I found myself in a place where I began to consciously borrow from competing paradigms to make sense of somatics. Through this process, I developed the idea of social somatic theory. ${ }^{2}$

While researching spirituality and postmodernism I also began to find that some scholars were beginning to break through the boundaries associated with spirituality and postmodernism and moving away from an 'either/ or' approach. For example, Besecke, 2001), embraces the idea of a reflexive spirituality, focused on culture; Gatens-Robinson (1984), proposes a feminist approach to spirituality, Riley (2002), addresses the return of the sacred in postmodern theory; Roof (1993), reconstructs the idea of religious space from a postmodern perspective; Sutherland et al. (2003), view religion and spirituality from an alternative health practices perspective, critically analysing the medicalization of health; Vento (2000), traces the rediscovering of the sacred, from the secular to a postmodern sense of the sacred; and Williamson (2010), includes postmodern and critical approaches to spirituality in her analysis of theoretical approaches to spiritualities. These 
postmodern writers present a pluralistic spirituality that connects to community, allows for divergent experiences and meaning, and bases spirituality on a constructed self and reality.

I concluded this narrative by reflecting on my final position:

Thinking back to my experiences and viewpoints about spirituality in relationship to somatics and postmodernism, I find some crossover areas. These definitions of spirituality including somatic, eastern-oriented and postmodern ideas tend to move away from an authoritative sense and move towards a more pluralistic definition. As Williamson suggests, 'personal spiritual truths and faiths are instrumentally shaped by the wider sociocultural landscape' and move away from religion as an institution (2010: 40). Thus, definitions of spirituality can be malleable. As somatics tends to embrace a more personal and subjective relationship to the world, postmodernism also recognizes that the world is not objective.

However, there still exists a tension between somatic/experiential definitions, and postmodern conceptualizations in these bodies of literature. While somatic and experiential descriptions tend to provide a relational experience to the world and value essence, truth and holism, postmodernism questions individualism, and materialism, while acknowledging fragmentation, difference and partial truths.

But my larger question is, 'Is there is a way to be able to negotiate these differences and still embrace parts of opposing world-views?' Perhaps we can if we are aware of these tensions and differences; and if we do not avoid the divergent epistemologies from which they arise.

Postmodernism, not only provides another way of viewing spirituality, but also addresses the state of the world. For example, in a world of difference, one that is getting smaller and cultures constantly moving, postmodernism acknowledges a certain juxtaposition of voices and view- points. Perhaps, to see a postmodern world is to see that different and opposing world-views can exist together. In this sense, one may be able to value aspects of one position while finding an affinity with a different world-view. In this spirit of postmodernism, I may be able to acknowledge the plurality of postmodernism and the acknowledgement of partial truths while holding on to a connection to experience. However, I believe that I must acknowledge that, for instance, somatics may not bring all the answers and, like everything, is value driven, that there is no knowledge that is value-neutral (see Johnson 1992). As suggested in former articles (Green 2000, 2001a, 2001b, 2002-2003, 2004a, 2004b) somatics, and now for that matter spirituality, should not be romanticized or seen as a panacea for all the world's ills but as a tool that may help us connect to the world and make visible key problems and issues. Without questioning our motives through a self-reflexive process, we may be repeating the grand narratives and partial truths we attempt to challenge. 
In other words, from a postmodern perspective, I see that experience is constructed. I can value experience but realize that my experiences contain partial truths, assumptions and biases that may not apply to disenfranchised groups or others.

I may find that my experiences are spiritual in the sense that they connect me to the world, but within a construction of that spirituality that is partial and not the same for everyone. Others may have other constructions of spirituality.

Thus for me, a postmodern spirituality is one that deconstructs reality, truth and knowledge, yet allows me to embrace experience and connection. In this postmodern sense I can acknowledge different epistemologies yet I can be aware that there are tensions between these schools of thought. This may seem to be an easy and useful conclusion to this discussion but the concept is one I can employ to speak honestly about how views often resist each other. (Green in press)

Thus, in this narrative, I use spirituality as an example of how I cross boundaries of philosophical thought regarding somatics and dance. I describe how I break the binaries of experiential and postmodern world-views, yet caution against merely bringing them together without analysis, without self-reflexivity, and without the recognition of the differences between these theories.

\section{Postpositivist Research and Science}

While the first narrative probes somatic and postmodern theories and world- views, the second story looks at research from the perspectives of somatics and science. It addresses the research process itself and the ideas grounding that process.

This second dilemma occurred when I was asked to collaborate with scientists on a somatics project. For years, I was sceptical about science being the only way to ask questions. My doctoral research methodology courses taught me that no knowledge is value-free and that there has been an established hierarchy in academe that embraces and rewards the hard sciences and rejects other methods of gathering information. While I did not wish to reject science or its contributions to health, I was aware of differences in philosophical grounding between science and postmodernism, or between positivism and postpositivism. As stated in a chapter I wrote with Sue Stinson,

Generally, positivists tend to assert that reality is found - that there is a real truth or big truth that we can know. Postpositivists, on the other hand, tend to believe that reality is socially constructed - that we construct reality according to how we are positioned in the world, and that how we see reality and truth is related to the perspective from which we are looking.

Epistemologically, positivists tend to assert that we can know a 'true' reality and by using objective research methods, we can uncover the 'truth.' In contrast, many postpositivist researchers reject the claim that research can be value-free or that one sole truth can be found through objective research methods. Furthermore, some postpositivists believe that subjectivity is not only unavoidable but may 
even be helpful in giving researchers and participants a more meaningful understanding of people and research themes. In accepting a socially constructed reality, we realize that our belief systems, or the stories we tell of who we are, may not be consistent and reliable in the positivist sense, because they vary each time we tell them.

Consequently, reliability, while a basic tenet of empirical scientific research, is regarded by qualitative researchers as equally impossible as objectivity.

(Green and Stinson 1999: 93-94)

With this approach to research, I found myself being cautious about what seemed to be occurring in higher education in the United States. It appeared to me that the field of somatics was being held under the umbrella of the dance sciences. During the Dancing in the Millennium Conference in Washington, DC in July 2000, I problematized the assumed connection between somatics and dance science:

Up until now, somatics has often been grouped along with the 'dance sciences.' There have been a number of conferences, symposiums, organizational committees, and publications, centred on the theme of 'dance science and somatics.' Further, course work required or offered at many major university and college dance programs is often envisioned around somatic study as an adjunct to the study of anatomy and kinesiology. Moreover, particular job openings often require experience in both dance science and somatics; they are often cojoined as a field of expertise.

(Green 2001c)

Although I note that there are good reasons why these fields are interrelated and acknowledge that science can be a foundation for many somatic practices, I believe that there are major differences between these approaches. Where the sciences generally view the body as an objective entity with particular characteristics that can be observed from a third-person perspective, somatics acknowledges the inner proprioceptive messages that inform the body. The two, therefore operate from a different epistemology, or way of knowing the world. 'Where the dance sciences seek objective truths, somatics may not seek truth, as measurable facts, but as how one constructs the body itself from a subjective viewpoint' (Green 2001c).

In addition, I maintained that somatics rejects a body/mind dualism. This split removes us from the experiences of our bodies and often results in disconnecting us from our own inner proprioceptive signals from our somas as living bodies. For example, a body in a distorted alignment - one often used as a model in western media - is likely to lead to a lack of ownership of the body because there is a lack of connection, and strength, while it may be difficult to move energy through such a 'model' body. While some poses may sell magazines and normalize a particular sexuality, they may create weak dancers. These dancers may be influenced by such ideals. By disconnecting people from their sensory and sensual selves, through the imposition of external models of 'ideal bodies', or standards of what the body 'should be' and how it should 
act, the dominant culture maintains control as people in oppressed groups distrust their own sensory impulses and give up their bodily authority. And, according to [Don] Johnson, it allows human exploitation and suffering to take place in the name of science (Green 2000).

Thus, coming from this perspective, I was deeply grounded in thought centred around social constructions of bodies. It did not seem likely that I would work in a scientific fashion or give up my work with social somatic theory. In honesty, I was set at one end of a binary conceptualization of body theory.

However, after sharing my interest in somatics, particularly in Kinetic Awareness ${ }^{\circledR}$ and health with a collaborative group in the areas of Public Health Education and Kinesiology, I was asked if I would be interested in collaborating on a study focused on women with breast cancer. My initial reaction was to kindly refuse the offer. But for some reason, I indicated that I might be interested. After the group brought in a consultant from exercise science and the project began to be framed around science and grant money, I was about to bow out gracefully because I felt I would have to give up the sociocultural aspect of my work. This consultant spent much of her time writing grants and doing scientific studies that support alternative interventions in health care. Her job was completely science oriented. She was granted enormous amounts of funding for her studies. I was quite intimidated and felt I could not possibly do this kind of research in my academic life. It would mean giving up every- thing I believed in.

But then I began to think about how this project may be helpful for women with breast cancer and also bring somatics and what I was doing in Kinetic Awareness ${ }^{\circledR}$ into a more public sphere. I let everyone know that I did not do scientific research and they said it would be interesting to have one person from Exercise Science do the quantitative part of the study and I do a qualitative part of the study. I still had reservations due to my political take on the subject but I figured I could write up my piece from my perspective and that I would have authority to shape my writing, but I was still concerned because I would have to address thematic areas such as sleep, quality of life, etc. and I did not do interventionist research as done in the health professions. But I figured that I could attempt to bring in my cultural/political slant while suiting their needs.

In addition, during this process, I began to hear more and more about dance and science collaborations and about topics that began to interest me such as brain science and chaos theory. While I had to negotiate two conflicting perspectives and approaches I began to wonder if it is possible to be situated in two places at one time.

Although difficult, the boundaries began to become more fluid for me. I asked if I was selling myself out and not sticking to my beliefs, but once again, I began to combine both aspects (health findings and social issues), in analysing the data and writing my article, and attempt to find the data that indicated particular health findings but also find social implications beyond the hard sciences. So I found a way to do this. However, in attempting to be more open, but still hold my ground epistemologically, I found myself in a difficult position. I ended up with a manuscript that I was not happy with because it did not sufficiently reflect my philosophical standing.

I am not saying that I would not want to go this route again because it did not allow me to have a consistent research agenda and positionality. But, I recognized the complexity of the issues and 
how we sometimes have to break what we see as binaries and not always look at everything as an either or proposition but allow for theoretical fluidity.

But again, I know from reviewing many manuscripts from new researchers, who seem to pick and choose aspects of paradigms that fit their needs, that there is a danger in fluid boundaries as well. First, it may be important to understand the differences and respect the boundaries before opening them up and moving through them.

\section{Discussion}

These two stories explain why I maintain the idea of a body as a social construction yet problematize a dogmatic approach that does not consider theoretical overlap.

These narratives provide examples of struggles working within theoretical frameworks that do not fit together so neatly. In addition, they address the need to let go of thinking in binaries without also acknowledging the problem of combing competing ideas without acknowledging the tensions between them. Although some somatic researchers and practitioners think of tension as something to release or get rid of, acknowledging tensions can lead to a deeper understanding of issues.

The stories suggest that there are tensions between somatic theory and practice, postmodernism, and scientific method. While postmodernism attempts to see what is missing and investigate partial narratives that are not neutral or value-free, somatic theory generally follows Thomas Hanna's conceptualization of somatics as a living body, separate from sociological, political or cultural influences.

However, the field has grown and expanded to include social somatic theory and theorists such as Don Johnson who recognize outside influences on bodies. In addition, there are critiques of somatic theory and charges that it does not necessarily acknowledge sociocultural aspects of constructed bodies. I, for one, critique essentialist dogma surrounding somatic thought through my writing on social somatic theory.

As another example, Isabel Ginot deconstructs Shusterman's theory of somaesthetics. Although she tends to define somatics as one way of thinking and practice, with one epistemology and does not recognize that somatics is a not a monolith, she does point out that it is problematic to view somatics as 'an antidote to dominant dance practices' (2010: 12). She looks at how somatics has been addressed, and finds, for example, its relationship to science problematic as well as its 'replacing a political and social conscience with a ìsomaticî conscience that views the subject as closed and autonomous' (2010: 23).

Ginot suggests that Shusterman's work is problematic because it has a limited focus that does not include major aspects of the work he cites. One way Shusterman's work is limited is that it aligns Foucault's thinking with his own idea of 'somataesthetics' and contends that Foucault's work represents a 'body consciousness' and experiential level of embodiment (Shusterman 2008). However, he does not consider the differences between Foucauldian and somatic views of bodies. Foucault looked at power and its relationship to knowledge. His studies approach the 
body as a site of social and political control and power. Although there are connections between somatic theory and Foucauldian thought, a number of tensions exist between these ways of thinking. For example, Foucault would not be fond of the idea of bodily experience and would be suspicious of the use of working pedagogically through the body. Although he viewed the body as a site of political manipulation and control and studied it as an effect of the culture in which we live, his writing suggests a suspicion of typical somatic conceptualizations such as bodily experience and practice (Foucault 1979, 1980). As Frank points out, 'What Foucault contributes to the study of the body - beyond his studies as a site of political violence is an enhanced selfreflectiveness about the project of the body itself' (1990: 132).

In other words, Foucault does not claim that the body can provide us with a grounded truth or that education through the body can free people from oppressive social policies and authoritarian regimes. His writing offers an approach rooted in a critique of institutions through discourses created by a dominant culture. He would be cautious about somatic practices because of his claim that experience is based on how our perceptions have been socially constructed. He would be leery of any claims to 'experiential' or 'somatic' authority.

In addition, Don Johnson (1992) points to the danger of using somatic practice as a panacea to the world's ills without framing the discourse in a larger social context. He suggests that by focusing solely on individualistic bodily experience, we may be hypnotizing ourselves to the outer world and the problems Foucault addresses through his historical analyses.

Nevertheless, it may be recognized that although Foucault rejected bodily practice and experience in his early career, towards the later part of his career he came to 'refute the autonomy of discourse' (McNay 1993: 27) and to refer to the corporeal aspect of life. He acknowledged, 'the discursive and material are linked together in a symbiotic relationship' (1993: 27). Thus, although he was more suspicious of experiential or corporeal notions of body in his early years, he grew to be more accepting of such aspects later in his life.

However, although Foucault did become more accepting of bodily conceptualizations later in his life, Shusterman sometimes misconstrues Foucault's intent. Shusterman criticizes sexual aspects of Foucault's work, but does not seem to be aware that the core of his work problematized a somaesthetics and found no solutions to the problem through somatic practice. Rather, he looked at the body through a historical lens and made his point through an analysis of language. I read Foucault's idea of 'care of the self' as a societal prescription emanating from organizations that attempt to control people through a focus on their own behaviour, not as a prescription for health and embodiment.

Thus Shusterman's alignment with Foucault may be falsely prescriptive. Shusterman never address how the experience of the body is influenced by anything outside of an individualistic view.

This may be one example of how the differences in thinking are often ignored in body theory and somatics. Shusterman's ideas are more fully aligned with Merleau Ponty and phenomenology because they both see the body as experience. But his writing about Foucault does not address the tensions between postmodern thought and somatics. 
In closing, through my stories I attempt to use reflexive accounts of scholarly work to demonstrate movement from being stuck in binaries to the recognition of the fluidity and complexities of thought regarding somatics, postmodernism and science. Yet at the same time, this cannot be accomplished without recognizing the full differences in approach and clarity of thinking while moving through the boundaries. I leave this methodological exercise believing that thinking in either or terms limit the scope of scholarship. Yet accepting all theory that addresses bodies is simplistic because it muddies the meaning of the message. I read Shusterman's work as a one-sided approach that attempts to sell ideas, rather than provide a critical analysis of the issues.

I continue to argue that somatic theory is not a closed box and somatic practice is not a panacea to all the world's ills. I have seen somatic practice used as a way to indoctrinate students or even abuse them, as in the case of a man who attempted to help his clients relive the experience of abuse, through the use of placing his body on top of them, thus reliving the assault. Yet I do find that it somatic practice can be a practical tool that may be used bring people in touch with their bodies even if they are socially constructed and fluid bodies.

In closing, I have no easy answers except to be aware of the inherent beliefs we adapt when embracing somatics without critical analysis. At the same time, I do not want to give up the experiential aspect of somatics. Dance research needs to be more than a cerebral process. But I feel a need for self- reflexivity when valuing experience as an individualistic and static concept.

We may be living in a period where it may be time to acknowledge both the value and humanity of our bodies in connection with the earth, and experience, while also critiquing the problems associated with thought in experience alone. It may be time to tear down the boundaries a bit while maintaining grounded thinking, consistent positions and acknowledging social constructions and culture.

\section{References}

Besecke, K. (2001), 'Speaking of meaning in modernity: Reflexive spirituality as a cultural Resource', Sociology of Religion, 62: 3, pp. 365-81.

Foucault, M. (1979), Discipline and Punish: The Birth of the Prison, New York, NY: Vintage.

— (1980), The History of Sexuality: Vol. 1. An Introduction (trans. R. Hurley), New York: Vintage Books.

Frank, A. (1990), 'Bringing bodies back in: A decade review', Theory, Culture \& Society, 7: 1, pp. 131-62.

Gatens-Robinson, E. (1984), 'Finding our feminist ways in natural philosophy and religious thought', Hypatia, 9: 4, pp. 207-228.

Ginot, I. (2010), 'From Shusterman's somaesthetics to a radical epistemology of Somatics', Dance Research Journal, 42: 1, pp. 12-29. 
Green, J. (1993), 'Fostering creativity through movement and body awareness practices: A postpositivist investigation into the relationship between somatics and the creative process', Ph.D., The Ohio State University, Columbus, OH.

(1996a), 'Choreographing a postmodern turn: The creative process and somatics', Impulse, 4: 4, pp. 267-75.

(1996b), 'Moving through and against multiple paradigms: Postpositivist research in somatics and creativity - Part I', Journal of Interdisciplinary Research in Physical Education, 1: 1, pp. 43-54.

(1996c), 'Moving through and against multiple paradigms: Postpositivist research in somatics and creativity - Part II', Journal of Interdisciplinary Research in Physical Education, 1: 2, pp. 73-86.

(1999), 'Somatic authority and the myth of the ideal body in dance education', Dance Research Journal, 31: 2, pp. 80-100.

(2000), 'Power, service, and reflexivity in a community dance project', Research in Dance Education, 1: 1, pp. 53-67.

(2001a), 'Emancipatory pedagogy? Women's bodies and the creative process in dance', Frontiers, 21: 3, pp. 124-40.

(2001b), 'Socially constructed bodies in American dance classrooms', Research in Dance Education, 2: 2, pp. 155-73.

(2001c), 'Towards a globalization of dance research: The scholarly disciplines', in J. LaPointeCrump (ed.), Congress on Research in Dance Conference Proceedings - Transmigratory Moves: Dance in Global Circulation, New York, NY: Congress on Research in Dance, pp. 156-60.

(2002-2003), 'Foucault and the training of docile bodies in dance education', Arts and Learning, 19: 1, pp. 99-126.

(2004a), 'The body politic: Constructions of health and healing in dance education', National Dance Education Conference Proceedings, East Lansing, MI: Michigan State University.

(2004b), 'The politics and ethics of health in dance education in the United States', in E. Anttila, S. Hamalainen and L. Rouhiainen (eds), The Same Difference? Ethics and Politics Embodied in Dance, Helsinki, Finland: Theatre Academy of Finland, pp. 65-76.

(2007), 'American body pedagogies: Somatics and the cultural construction of bodies', Congress on Research in Dance Conference Proceedings Choreographies of Migration:

Patterns of Global Mobility, New York, NY: Congress on Research in Dance, pp. 85-89.

(2008), 'Les politiques et éthiques de la santé en éducation de la danse au Etats-Unis', in S. Fortin (ed.), Les politiques et éthiques de la santé en éducation de la danse au Etats-Unis, Presses de l’Université du Québec à Montréal, Collection Santé, pp. 169-80.

(2015), 'Postmodern spirituality?: A personal narrative', in A. Williamson (ed.), Dance, Somatics and Spiritualities: Contemporary Sacred Narrative. Leading Edge Voices in the Field, Coventry, UK: Intellect. 
Green, J. and Stinson, S. (1999), 'Postpositivist research in dance', in S. H. Fraleigh and P. Hanstein (eds), The Art of Research: Systematic Inquiry in Dance, Pittsburgh, PA: University of Pittsburgh Press, pp. 91-123.

Johnson, D. (1992), Body: Recovering our Sensual Wisdom, Berkeley: North Atlantic Books and Somatic Resources.

McNay, L. (1993), Foucault and Feminism, Boston, MA: Northeastern University Press. Riley, A. T. (2002), 'Durkheim contra Bergson? The hidden roots of postmodern theory and the postmodern "Return" of the sacred', Sociological Perspectives, 45: 3, pp. 243-65.

Roof, W. C. (1993), 'Toward the year 2000: Reconstructions of religious space', Annals of the American Academy of Political and Social Science, 527, May issue, pp. 155-170.

Shusterman, R. (2008), Body Consciousness: A Philosophy of Mindfulness and Somaesthetics, Cambridge, UK: Cambridge University Press.

Sutherland, J. A., Poloma, M. M. and Pendelton, B. F. (2003), 'Religion, spirituality, and alternative health practices: The baby boomer and the Cold War cohorts', Journal of Religion and Health, 42: 4, pp. 315-38.

Vento, A. C. (2000), 'Rediscovering the sacred: From the secular to a postmodern sense of the sacred', Wicazo Sa Review, 15: 1, pp. 183-205.

Williamson, A. (2010), 'Reflections and theoretical approaches to the study of spiritualities within the field of somatic movement dance education', Journal of Dance \& Somatic Practices, 2: 1, pp. $35-61$.

\section{Suggested Citation}

Green, J. (2015), 'Moving in, out, through, and beyond the tensions between experience and social construction in somatic theory', Journal of Dance \& Somatic Practices 7: 1, pp. 7-19, doi: 10.1386/jdsp.7.1.7_1

1. Portions of this section are part of a forthcoming chapter Green (in press).

2. Social Somatic Theory draws on the ideas of such writers as Don Johnson and Elizabeth Behnke who addressed issues of bodily authority and demonstrates how our bodies are shaped by the cultures in which we live. From this perspective, western culture creates the myth of a body/mind split. However, this split does not simply separate our minds from our bodies and favour mind over body. Rather there is an active obsession with the body as an objective, mechanical entity. There is a focus on the body, but as a mechanical instrument rather than as a soma. Through the normalization of what bodies should be and how they should act the dominant culture maintains control as people give up their bodily authority. It should be said that this theory might be used in an affirmative way as people are afforded more agency as the body is used as resistance to cultural norms.

\section{Contributor Details}


Jill Green Ph.D., is a professor of dance at The University of North Carolina at Greensboro. She is Director of Graduate Studies, conducts research and teaches somatics, body studies, research and pedagogy. In addition, she is a certified Kinetic Awareness ${ }^{\circledR}$ Master Teacher and directs a teaching programme at her studio. Her work is published in a number of journals and books. Dr Green is a Fulbright Scholar (Finland) and former co-editor of Dance Research Journal.

Contact: Professor and Director of Graduate Studies Department of Dance The University of North Carolina at Greensboro P.O. Box 26170, Greensboro, NC 27402-6170, USA. E-mail: jigreen@uncg.edu

Jill Green has asserted her right under the Copyright, Designs and Patents Act, 1988, to be identified as the author of this work in the format that was submitted to Intellect Ltd.

Copyright of Journal of Dance \& Somatic Practices is the property of Intellect Ltd. and its content may not be copied or emailed to multiple sites or posted to a listserv without the copyright holder's express written permission. However, users may print, download, or email articles for individual use. 